\title{
Saúde mental em tempos de pandemia: qual o impacto do Covid-19?
}

Mental health in pandemic times: what is the impact of Covid-19?

Salud mental en tiempos de pandemia: ¿cuál es el impacto de Covid-19?

Como citar este artigo:

Pinheiro, Guilherme Emanuel Weiss; Kocourek, Sheila. Saúde mental em tempos de pandemia: qual o impacto do Covid-19?. Revista Cuidarte. 2020;11(3):e1250. http://dx.doi.org/10.15649/cuidarte.1250

\section{Revista Cuidarte \\ Rev Cuid. 2020; 11(3): e1250 \\ doi" http://dx.doi.org/10.15649/cuidarte.1250

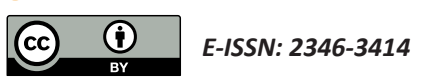

(1) Guilherme Emanuel Weiss Pinheiro

(1) Sheila Kocourek ${ }^{2}$

1 Enfermeiro, Doutor pelo Programa de Pós-Graduação em Enfermagem da Universidade Federal de Pelotas, Professor de Ensino Básico, Técnico e Tecnológico no Colégio Politécnico da Universidade Federal de Santa Maria, Santa Maria, Brasil. E-mail guilhermeewp@politecnico. ufsm.br Autor Correspondente.

2 Assistente Social, Doutora pelo Programa de Pós-Graduação em Serviço Social da PUCRS, Professora Associada na Universidade Federal de Santa Maria, Santa Maria, Brasil, E-mailsheilakocourek@gmail. com

\section{Prezada Editora:}

No final do ano de 2019, surgiu na China, na província de Hubei, vinculada a um mercado de frutos do mar, uma doença que causava uma forma de pneumonia grave até então desconhecida. A infecção foi associada ao vírus SARS-CoV-2, o sétimo vírus da família dos coronavírus que atingem os seres humanos ${ }^{1,2}$.

A partir de 21 de janeiro de 2020 a Organização Mundial de Saúde iniciou a publicação diária de Relatórios de Situação da Doença de Coronavírus (COVID-19), o primeiro demonstrou uma rápida disseminação do vírus na China, na Tailândia, no Japão e na Coreia do Sul ${ }^{3}$. Ao ponto que o relatório de número 26 (15 de fevereiro de 2020) demonstrou que o novo coronavírus estava presente em cinco continentes (África, América, Ásia, Europa e Oceania), apresentando a rápida disseminação da doença pelo planeta ${ }^{4}$.

No Brasil, a primeira confirmação oficial, por parte do Ministério da Saúde, ocorreu no dia 26 de fevereiro, e no dia 3 de março o número já era de 2 casos confirmados, ambos com histórico de viagem à Itália ${ }^{5,6}$. Assim, o Brasil passou a constar no relatório da Organização Mundial de Saúde a partir do dia 27 de fevereiro de 20207.

A partir disso, os casos vêm aumentando em proporções exponenciais e, quase três meses depois (14/05/2020), o país encontra-se com 203.165 casos confirmados e 13.999 óbitos decorrentes de infecção pelo novo coronavírus ${ }^{8}$. Sem contar com a subnotificação alertada por especialistas, uma vez que o Brasil é um dos países que menos realiza teste em proporção à sua população9 .

Recibido: mayo 15 de 2020

Aceito: junio 16 de 2020

Publicado: septiembre 1 de 2020 $\square *$ Correspondência Guilherme Emanuel Weiss Pinheiro E-mail:guilhermeewp@politecnico.ufsm.br 
Se por um lado tem-se um vírus ainda pouco conhecido, no que diz respeito a sua exata forma de transmissão e aos efeitos no organismo das pessoas, soma-se o fato de serem baixas as taxas de testagem. Este quadro demonstra que não há uma dimensão exata com o que se está lidando e suas proporções ${ }^{10}$.

Com isso, várias medidas vêm sendo tomadas pelas autoridades dos diferentes entes federativos - união, estados, municípios e distrito federal. Alguns com restrições mais duras em relação ao isolamento social e ao fechamento do comércio e circulação de pessoas no tecido urbano, já outros com medidas mais brandas. $O$ consenso gira em torno de que as atividades educacionais, nos diversos níveis de formação (desde a educação infantil até a pós-graduação), estão ocorrendo de forma virtual e na impossibilidade desta modalidade encontram-se suspensas, bem como todas as formas de aglomeração, como estratégias de conter a disseminação do vírus.

Na América Latina as medidas de isolamento social e cuidados com higiene requeridas assumem características particulares, isso porque muitas vezes elas não podem ser cumpridas. O não cumprimento se deve pelas condições objetivas de parcela da população, visto que não tem acesso a abaste-

Na América Latina as medidas de isolamento social e cuidados com higiene requeridas assumem características particulares, isso porque muitas vezes elas não podem ser cumpridas. O não cumprimento se deve pelas condições objetivas de parcela da população, visto que não tem acesso a abastecimento de água, saneamento básico e uma unidade habitacional adequada. cimento de água, saneamento básico e uma unidade habitacional adequada. Além disso, são muitos os trabalhadores informais, subempregados e desempregados os quais veem ruírem suas condições objetivas de vida, mais do que nunca.

Dentre os diferentes reflexos que esta situação de pandemia vem apresentando à sociedade, destaca-se a incerteza nos aspectos de tratamento e prevenção (ainda não há vacinas e tratamentos eficazes devidamente comprovados), as incertezas do ponto de vista econômico (aumentou o número de pessoas desempregadas e muitos impossibilitados de realizar suas atividades, em especial os informais), as incertezas de retorno das atividades (não há previsão de liberação); o distanciamento como algo que contribui para o adoecimento mental; a possibilidade de infecção pelo novo coronavírus; a possibilidade de colapso dos sistemas de saúde; entre outras questões delicadas do momento.

Autores que discutem situações de catástrofes afirmam que podem ser naturais ou provocadas pelas pessoas, ainda climáticas ou tecnológicas, esperadas ou imprevisíveis; e afetam as pessoas de diferentes formas ${ }^{11}$. Nesse contexto, a pandemia do novo coronavírus pode se enquadrar como uma situação de emergência e, ao observar, que se trata de uma doença altamente transmissível e os indicadores de gravidade clínica também sugerem alta gravidade ${ }^{10}$, pode-se dizer que se trata de uma catástrofe imprevisível.

Outro aspecto que se deve atentar é que as pessoas contaminadas e que evoluem para um quadro infeccioso grave, e por consequência indo a óbito, ficam distanciadas da família às vezes por dias ou semanas. Nesses casos de óbito a família fica impedida de fazer os ritos de despedida, gerando sofrimento e dificuldade em elaborar o luto, desencadeando transtornos psicossomáticos. 
A Organização Mundial de Saúde, ao discutir a saúde mental nas emergências, afirma que alguns transtornos mentais pré-existentes tendem ao agravamento após uma situação de catástrofe. $E$, ainda, há a introdução de outras situações como luto, ansiedade, uso e abuso de álcool e outras drogas, entre outros, embora as pessoas enfrentem as situações adversas de formas individuais e diferentes entre $\mathrm{si}^{12}$.

Nesse sentido é necessário que os gestores se ocupem da elaboração de um plano de respostas a saúde mental e atenção psicossocial no cenário da pandemia, sobretudo por se tratar de uma catástrofe imprevisível. Este plano pode abarcar estratégias de promoção da saúde mental, por meio do estímulo dos cuidados solidários na comunidade, atividades artísticas, culturais e religiosas adaptáveis, atentando para as orientações de biossegurança. Essas e outras estratégias promovem um sentimento de acolhimento e de pertencimento das pessoas, elas passam a se sentir menos solitárias e, portanto, o risco de adoecimento é reduzido. Além disso, o sistema de saúde não fica onerado com a contratação de mais profissionais para dar conta do adoecimento em $\mathrm{si}^{13}$.

Não se descarta a relevância da rede de atenção psicossocial organizada e apta a atender situações em que um processo patológico está sendo instaurado, aí sim torna-se necessário oferta de serviços de maior complexidade com a presença de profissionais qualificados e disponibilidade de psicotrópicos às pessoas que necessitem deste suporte.

Neste sentido, o Brasil, país que conta com o Sistema Único de Saúde, sendo um sistema com acesso universal, tem em sua base legal a prerrogativa de desenvolver ações nos diferentes níveis, a saber: promoção da saúde, prevenção de doenças, proteção, diagnóstico, tratamento, reabilitação, redução de danos, cuidados paliativos e vigilância em saúde ${ }^{14}$. Portanto, em alinhamento com a Organização Mundial de Saúde esse sistema busca privilegiar o enfoque à saúde e não à doença.

Com isso, a saúde mental precisa ser olhada com o viés da produção de saúde e não na ótica da patologia. Sistemas universais privilegiam esta lógica, em contraponto a outros modelos de sistemas, como o seguro-saúde, no qual o olhar

Com isso, a saúde mental precisa ser olhada com o viés da produção de saúde e não na ótica da patologia. é focado para o adoecimento da pessoa segurada. Portanto, há que se investir e expandir os sistemas universais de modo a proporcionar o acesso aos serviços de saúde de maneira organizada, sistematizada e integral.

Mediante o atual cenário, da pandemia do novo coronavírus, no que tange à saúde mental entende-se que os transtornos psicossociais podem ser evitados com base em ações de promoção da saúde mental. Sendo assim, é necessário trabalhar com os sentimentos que afloram neste período, tais como tristeza, raiva, impotência, insegurança, entre outros, sem categorizá-los como transtorno mental. Com isso, não se deve perder de vista que essas questões estão sendo vividas pelo coletivo, ainda que com particularidades, e precisam ser abordadas como tais. 


\section{Referências}

1. Wu F, Zhao S, Yu B, Chen YM, Wang W, Song ZG, et al. A new coronavirus associated with human respiratory disease in China. Nature. 2020;579(7798):265-69. https://doi.org/10.1038/s41586-020-2008-3

2. Zhu N, Zhang D, Wang W, Li X, Yang B, Song J, et al. A novel coronavirus from patients with pneumonia in China. 2019. N Engl J Med. 2020;382:727-33. https://doi.org/10.1056/NEJMoa2001017

3. World Health Organization. Novel coronavirus (2019-nCoV): situation report - 1 [Internet]. 2020 Jan [cited 2020 May 12]. Available from: https://www.who.int/docs/default-source/ coronaviruse/situation-reports/20200121-sitrep-1-2019-ncov.pdf?sfvrsn=20a99c10_4

4. World Health Organization. Novel coronavirus (2019-nCoV): situation report - 26 [Internet]. 2020 Feb [cited 2020 May 12]. Available from: https://www.who.int/docs/default-source/ coronaviruse/situation-reports/20200215-sitrep-26-covid-19.pdf?sfvrsn=a4cc6787_2

5. Brasil. Ministério da Saúde. Brasil confirma primeiro caso da doença [Internet]. 2020 Feb [cited 2020 May 13]. Available from: https://www.saude.gov.br/noticias/agencia-saude/46435-brasil-confirma-primeiro-caso-de-novo-coronavirus

6. Croda JHR, Garcia LP. Resposta imediata da Vigilância em Saúde à epidemia da COVID-19. Epidemio/ServSaúde.2020;29(1):e2020002.https://doi.org/10.5123/S1679-49742020000100021

7. World Health Organization. Novel coronavirus (2019-nCoV): situation report - 38 [Internet]. Geneva: World Health Organization; 2020 Feb [cited 2020 May 12]. Available from: https://www.who.int/docs/default-source/coronaviruse/situation-reports/20200227-sitrep-38-covid-19.pdf?sfvrsn=2db7a09b_4

8. Brasil. Painel Coronavírus [Internet]. 2020 [cited 2020 May 15]. Available from: https://covid.saude.gov.br/

9. Basso M. Subnotificação dificulta combate à covid-19 no Brasil [Internet]. 2020 Mar [cited 2020 May 13]. Available from: https://www.dw.com/pt-br/subnotifica\%C3\%A7\%C3\%A3o-dificulta-combate-\%C3\%A0-covid-19-no-brasil/a-52919120

10.Freitas ARR, Napimoga M, Donalisio MR. Análise da gravidade da pandemia de Covid-19. Epidemiol. Serv. Saúde. 2020;29(2):e2020119. http://dx.doi.org/10.5123/s1679-49742020000200008

11.Franco MHP. A Intervenção psicológica em emergências: fundamentos para a prática. São Paulo: Summus Editorial, 2015

12.World Health Organization. Mental Health in Emergencies [Internet]. 2019 Jun [cited 2020 May 13]. Available from: http://www.who.int/news-room/fact-sheets/detail/mental-health-in-emergencies

13.Chen Q, Liang M, Li Y, Guo J, Fei D, Wang L, et al. Mental health care for medical staff in China during the COVID-19 outbreak. Lancet Psychiatry. 2020;7(4) e15-e16. https://doi.org/10.1016/S2215-0366(20)30078-X

14.Brasil. Ministério da Saúde. Portaria № 2.436, de 21 de setembro de 2017. Aprova a Política Nacional de Atenção Básica, estabelecendo a revisão de diretrizes para a organização da Atenção Básica, no âmbito do Sistema Único de Saúde (SUS). Diário Oficial da União. 22 Set 2017. 